Revista de Estudios Histórico-Jurídicos

[Sección Bibliografía]

XXXII (Valparaíso, Chile, 2010)

[pp. 515 - 529]

\title{
La Justicia Vindicatoria y el Status de la Antropología Jurídica
}

\author{
RAFAEL RAMis BARCELÓ* \\ Universidad Pompeu Fabra, Barcelona
}

\section{INTRODUCCIÓN}

Este tomo de mil páginas es, hasta donde alcanzo, la explicación más amplia y detallada -en cualquier idioma- de la justicia vindicatoria ${ }^{1}$. Su autor, Ignasi Terradas Saborit, catedrático de Antropología de la Universidad de Barcelona, compendia en esta voluminosa obra muchos años de estudio. Un somero resumen del libro exigiría un comentario bibliográfico de una extensión mayor que la de un artículo. No es ésa mi ambición, pues ni la parquedad de mis conocimientos antropológicos ni mi capacidad de síntesis permiten empresas de tal calibre.

El presente escrito tiene otra intención. Más que una descripción del libro, me gustaría subrayar algunos puntos especialmente novedosos y complejos de esta obra. Dejo sentada, antes de adentrarme en estas cuestiones, mi profunda admiración por ella, que en una dimensión global me parece casi inatacable. Sólo tras la profundización en algunos aspectos historiográficos y metodológicos se pueden poner de relieve ciertos problemas hermenéuticos, que no desdicen en ningún momento el valor integral de la obra. Antes al contrario, creo que a través de los comentarios que siguen se podrá aquilatar más adecuadamente el peso de esta obra y estimar la dificultad de escribir un volumen de este alcance y dimensiones.

* Facultat de Dret, Universitat de les Illes Balears. Dirección postal: Ctra. de Valldemossa, km.7.5, 07122 Palma de Mallorca, España. Correo electrónico, rafael.ramis@upf.edu. Estoy muy agradecido por la ayuda y el apoyo que me han prestado los profesores Tomàs de Montagut, Manuel J. Peláez y Josep María Vilajosana.

${ }^{1}$ Terradas Saborit, I., Justicia vindicatoria, de la ofensa e indefensión a la imprecación y el oráculo, la vindicta y el talión, la ordalía y el juramento, la composición y la reconciliación (Madrid, CSIC, 2008), 1007 págs. 


\section{DOS POSIBLES INTERESES}

Creo que el libro responde a dos intereses: uno de ellos manifiesto, y el otro, velado. Una obra titulada Justicia vindicatoria: de la ofensa e indefensión a la imprecación y el oráculo, la vindicta y el talión, la ordalía y el juramento, la composición y la reconciliación pretende ser un análisis de todas estas formas de justicia, generalmente de carácter premoderno. Hasta el momento, los estudios antropológicos sobre la justicia vindicatoria habían sido empíricos desde Malinowski² ${ }^{2}$ si bien estaban caracterizados por su carácter fragmentario. En lo tocante a la Historia del derecho las recopilaciones heurísticas han sido hasta el momento presente las aproximaciones más rigurosas a los modos de justicia vindicatoria.

Sin embargo, pocos libros -y desde luego ninguno de estas dimensiones- habían intentado abordar el tema desde una perspectiva teórico-práctica, es decir, mediante aquella en la que el estudioso de los archivos y del trabajo de campo vuelve la vista atrás y se preocupa de establecer, a posteriori, unas pautas generales y abstractas que ayuden a comprender de forma unitaria el núcleo de su libro -en este caso de la "justicia vindicatoria"- expresado como un concepto.

Existen varias formas de "teorizar" sobre tal fenómeno jurídico y social. Una posible vía para aproximarse a la "justicia vindicatoria" hubiese sido la "teoría del derecho", estudiando la dimensión normativa y axiológica, si bien se hubiese pagado el duro peaje de abandonar el sentido casuístico y empírico, que hasta ahora habían descrito los historiadores del derecho y los estudiosos de la antropología social. La labor de estos dos últimos se centra, precisamente, en la descripción, pero también en la interpretación. El problema se encuentra en que si la dimensión interpretativa deviene simplemente exégesis material, todos los estudios, por ejemplo, sobre composiciones u ordalías no traspasan la barrera de la abstracción. Si no hay tal abstracción, jamás se puede llegar a establecer una "teoría" unitaria que responda a las preguntas básicas sobre el significado de tal o cual comportamiento social. Muchos ejemplos histórico-jurídicos son verdaderas obras maestras en su precisión histórica, legal e incluso filológica, pero no tienen la intención de determinar qué es una imprecación, cuáles son las condiciones de posibilidad que la permiten o cuál es su valor ético, psicológico o teológico.

En el libro del profesor Terradas existe desde un primer momento la voluntad de estudiar tanto la dimensión empírica como la teórica de la justicia vindicatoria, y escoge -dada su especialidad- el camino de la "antropología jurídica". He dicho antes que el libro tenía un propósito manifiesto, y creo que es éste: comprender la justicia vindicatoria desde la antropología jurídica. Se trata de una decisión del todo comprensible en un antropólogo, pero a su vez abre un interrogante: ¿qué "antropología jurídica"?

Y la contestación de la pregunta genera dos cuestiones más: cómo definir la disciplina y qué método seguir para estudiarla. La definición de la antropología y su división en diferentes ramas obligan a tomar partido. El desencanto actual de la antropología social con sus propias subdivisiones clásicas (parentesco, económica...)

\footnotetext{
${ }^{2}$ Véase, Harris, M., El desarrollo de la teoría antropológica, historia de las teorías de la cultura (Madrid, Siglo XXI, 2003), pp. 472 ss. Más concretamente, puede verse: FALK MoORE, S., Certainties Undone, Fifty Turbulent Years of Legal Anthropology, 1949-1999, en The Journal of the Royal Anthropological Institute, 7 (2001), pp. 95-116.
} 
o contemporáneas (política) obliga asimismo al estudioso actual a posicionarse en el debate actual entre los partidarios de esta fragmentación y los del holismo ${ }^{3}$.

Si el propósito manifiesto de Ignasi Terradas era estudiar la justicia vindicatoria desde el punto de vista de la antropología, tenía que justificar previamente su opción metodológica, lo que le conduciría hacia una u otra de las ramas de la antropología. Finalmente el autor se decide, como dice varias veces a lo largo del libro, a ceñirse a la antropología social, pero abierta al realismo. Si Lévi-Strauss o Malinowski, en sus respectivos esquemas conceptuales habían dibujado relaciones sociales de carácter "jurídico", Terradas reclama para la antropología actual una apertura hacia el fenómeno jurídico expresado en la espontaneidad y la inmediatez, así como en las conductas reales de los individuos, en un desarrollo de la obra de Lewellyn ${ }^{4}$.

Esta elección del autor determina el enfoque general del libro, que manifiesta sus diferencias tanto con la antropología estructuralista, la materialista o la posmoderna. Terradas es un autor muy consciente del diálogo con la propia tradición antropológica, y por esa razón quiere hacer partícipe en todo momento al lector de sus decisiones metodológicas. Sabe que la denominación "antropología jurídica” podría resultar engañosa, pues su status académico y metodológico dista de ser claro y unánime, sobre todo en España y en Hispanoamérica ${ }^{5}$. Así pues, en Justicia vindicatoria ha querido, a la vez, escribir un trabajo de altura sobre este tema, y reivindicar una orientación metodológica para el estudio de la antropología jurídica. El primero sería el objetivo confesado, y el segundo el no confeso o indirecto.

Respecto del segundo hay que recalcar que Terradas, en el libro, no sólo tiene que hacer frente al problema del estudio de las fuentes y a la inevitable tensión entre teoría y praxis que se produce en toda obra antropológica, sino que se ve obligado a abordar previa o, en todo caso, simultáneamente, el conjunto de problemas metodológicos y conceptuales necesarios para configurar $-\mathrm{O}$, en este caso, reconfigurar- una disciplina. Esta obra es por tanto un auténtico compendio sobre la justicia vindicatoria, a la vez que se erige en la primera columna de un enfoque disciplinar novedoso en España.

Por eso, el profesor Terradas se ve obligado, antes de empezar su exposición, a desentrañar ciertas ambigüedades con respecto al objeto y al método de su "antropología jurídica”. En particular, esta obra se opone, por ejemplo, a la de un Norbert Rouland $^{6}$, un historiador del derecho que defiende una "antropología jurídica" tal vez demasiado etnocéntrica y, pese a sus buenas intenciones, basada en un modelo no muy distante de la antropología de la época colonial, y quizás excesivamente "cerrada" en sí misma7.

El modelo que Terradas defiende se encuentra más cerca de la obra de Louis

${ }^{3}$ Véase: Olivier de Sardan, J. P., Anthropology and Development Understanding Contemporary Social Chang (London, Editorial Zed Books, 2005).

${ }^{4}$ Llewellyn, K. N. - Hoebel, E. A., The Cheyenne Way, Conflict and Case Law in Primitive Jurisprudence (Oklahoma, The University of Oklahoma Press, 1941).

${ }^{5}$ Destáquense, Terradas, I. (coordinador), Antropología Jurídica. Actas del VIII Congreso de Antropología (Santiago de Compostela, 1999); y KROTZ, E. (editor), Antropología jurídica, perspectivas socioculturales en el estudio del derecho (Barcelona, UAM-Anthropos, 2002).

${ }^{6}$ Rouland, N., Anthropologie juridique (Paris, PUF, 1988).

${ }^{7}$ Véase: González Galván, J. A., La enseñanza de la antropología jurídica en Francia, en Etnicidad y derecho. Un diálogo postergado entre los cientificos sociales (México, Instituto de Investigaciones Jurídicas, UNAM, 1996), p. 298. 
Assier-Andrieu", que no tiene la vocación de "traducir" al lenguaje de Occidente unas prácticas que se dan en los territorios "salvajes", ni mucho menos la de servir como pauta occidental para conocer unas sociedades aún por civilizar, pero con las que se tiene que dialogar irremediablemente. Assier-Andrieu y Terradas coinciden en la necesidad de "aprender" con y de los otros, de manera que indirectamente reivindican y-después del debate de los ochenta y de los noventa- rehabilitan la dimensión dialógica de muchos de los antropólogos de principios del siglo XX.

Esta "reconfiguración" de la antropología jurídica supone algunos matices con respecto de la disciplina clásica denominada "antropología social”, y con la más reciente, llamada "antropología política". Terradas parece que no quiere entrar en la batalla terminológica y que, hasta cierto punto, estaría dispuesto a conceder que la antropología jurídica, tal y como él la concibe, sería una antropología social en su vertiente más realista, o también una antropología política, siempre y cuando se enfaticen los problemas de la identidad real, más que los de la identidad simbólica de Geertz?.

Así pues, sin enfrentarse directamente a las concepciones de Godelier o de Balandier ${ }^{10}$, muy influidas por el marxismo, Terradas prefiere configurar una antropología jurídica abierta a las demás disciplinas sociales, de modo que no tenga una completa autonomía, sino que precisamente necesite de las demás. Mediante este paso, el autor se aleja de la antropología "correctora" de las teorías sostenidas por las demás ciencias sociales, y defiende una antropología jurídica integradora, en la que puedan caber, como mínimo, las investigaciones de juristas, sociólogos, antropólogos e historiadores.

La justificación de tal modelo se encuentra en una búsqueda de las raíces de un modelo de antropología jurídica tanto en las obras de los padres de la sociología como en algunos juristas del XIX, ajenos al fenómeno positivista y a la dogmática del derecho. De ahí que Terradas dedique bastantes páginas a la obra de Durkheim ${ }^{11}$, poniendo de relieve los avances de su funcionalismo, pero también indicando los límites de una obra que no se había abierto suficientemente al realismo, empecinada en la distinción conceptual entre la solidaridad orgánica y la mecánica. He aquí una de las razones por las que la investigación sociológica y antropológica sobre el derecho no terminó de cuajar, mientras que el realismo de historiadores como Fustel de Coulanges generó un interés por las formas espontáneas de la práctica jurídica y por lo no normado, como expresión tácita del derecho o de la justicia ${ }^{12}$.

Terradas busca una conexión con las teorías de Durkheim y la obra de un historiador de las instituciones como Fustel de Coulanges o, ya en pleno siglo XX, con filósofos del derecho como Paul Vinogradoff. Este último autor, casi olvidado en nuestros días, representa una curiosa conexión de la historia del pensamiento jurídico con la politeia aristotélica y la ética del sentido común ${ }^{13}$. Para Terradas, la apertura de la

${ }^{8}$ Véase esencialmente: Le droit dans les sociétés humaines (Paris, Nathan, 1996).

${ }^{9}$ Justicia vindicatoria, cit. (n. 1), p. 21.

${ }^{10}$ Véase el juicio crítico de la "antropología política" en Balandier que hace Guerreau, A., El futuro de un pasado. La Edad Media en el siglo XXI (Barcelona, Crítica, 2002), pp. 186-190. En Guerreau se encuentra una defensa de una posición "holística" sobre la antropología que está emparentada con la de I. Terradas. Sería, en este caso, una cierta apertura de la historia a la antropología.

${ }^{11}$ Justicia vindicatoria, cit. (n. 1), pp.30-48.

${ }^{12}$ Ibíd., p. 199.

${ }^{13}$ VinogradofF, P., Common-Sense in Law (New Jersey, The Lawbook Echange Ltd. Clarke, 2006). 
antropología a este sentido común -estudiado generalmente en la ética y en la filosofía jurídica- invita al realismo en la configuración del pensamiento y de la práctica jurídica. A su vez, el estudio teórico y empírico sobre estos usos sociales caracterizados por su realismo permiten la configuración de un crisol común, denominado "antropología jurídica” que aúne, en una síntesis final, las contribuciones de historiadores, juristas, sociólogos y antropólogos.

El autor no da el paso de incluir esa "antropología jurídica" en el seno de una "filosofía del derecho" de la que, por otra parte, recaba muchos estímulos ${ }^{14}$. Creo que las razones que le mueven a no hacerlo son varias: principalmente, por la búsqueda de una denominación menos cargada semánticamente, pues ayuda a evitar el predominio de una disciplina sobre otras, así como también cabe destacar que la "antropología", por su frágil equilibrio entre teoría y estudio empírico, invita al diálogo de las diferentes disciplinas sin que los excesos teóricos o prácticos de unas puedan ahogar la contribución de las demás.

Así pues, el alcance de la "antropología jurídica" se encuentra, para Terradas, condicionado por el diálogo con los otros estudiosos, a la vez que se dirige a la plasmación de lo universal y de lo común que hay en las sociedades. La "antropología jurídica" se encuentra más allá del diferencialismo que propugnan como objeto muchos estudiosos de la antropología cultural. La obra de Vinogradoff, que busca el sentido común en el derecho y en la sociedad se dirige a una reconstrucción de los rasgos comunes en la variedad de las sociedades humanas. Esta visión, muy cercana a la pretensión aristotélica, propugna una "antropología jurídica" en la que se destaque el contraste entre elementos comunes. A partir de ella, Terradas desecha como prioridad -o como labor única- la del estudio de los derechos indígenas o de las minorías étnicas o religiosas ${ }^{15}$.

Terradas, para lograr dichos fines, procura perfilar al máximo las fuentes de trabajo para el estudioso de la "antropología jurídica", de forma que aglutine la labor heurística y hermenéutica previa de los historiadores, sociólogos, juristas o de otros antropólogos. La labor de quien cultiva la "antropología jurídica" consiste, según el autor, en estudiar una serie de "casos-problema" y de establecer una teoría general sobre ellos.

En este sentido, Terradas reivindica la obra de Lewellyn y Hoebel ${ }^{16}$, pues en la antropología jurídica se debe estudiar cada uno de los casos desde que se genera el conflicto hasta que se resuelve. Todas las claves sociales, históricas, religiosas... ayudan a entender con precisión la forma de resolver el problema. Se trata de estudiar la ley y el derecho operando "en su matriz cultural", recogidos en un testimonio vivo por

${ }^{14}$ Un posible foco de estudio de la justicia vindicatoria es la filosofía del derecho. Siguiendo la pretensión realista aristotélica de Terradas, puede verse el reciente trabajo de EnGLARD, I., Corrective \& Distributive Justice. From Aristotle to Modern Times (Oxford, Oxford University Press, 2009), en la que se estudia la justicia como retribución desde la Ética Nicomáquea (11232a2-5) hasta nuestros días.

${ }^{15}$ Justicia vindicatoria, cit. (n. 1), p. 63. En el campo de la historia del derecho, y en el campo de la antropología jurídica de la Modernidad, el profesor Bartolomé Clavero defiende también que para el conocimiento del pensamiento jurídico moderno es necesario conocer sus bases morales y teológicas, La diferencia con Terradas es que la metodología de Clavero se encuentra mucho más cercana a la arqueología foucaultiana, fundamentalmente en temas de minorías y de indigenismo. Véase: Clavero, B., Tantas personas como estados. Por una antropología politica de la historia europea (Madrid, Tecnos, 1986).

${ }^{16}$ Justicia vindicatoria, cit. (n. 1), pp. 665-666. 
historiadores, juristas o antropólogos, que facilita una gran cantidad de información empírica.

La "antropología jurídica”, por tanto, se centra en la recogida de datos y en el diálogo con las demás disciplinas sociales. Cuando he dicho antes que el libro tiene un propósito no confesado es precisamente éste: mostrar un camino para el estudio de la antropología jurídica a partir de la reivindicación del realismo de algunos antropólogos y juristas del siglo XX.

\section{LA ESTRUCTURA DE LA OBRA}

Al ser una obra pionera en el mundo hispano en cuanto al método y al objeto, Ignasi Terradas dedica muchas páginas a su defensa, pues no sólo tiene que mostrar las ventajas para el estudio de la antropología jurídica en general, sino que también tiene que enseñar su adecuación a la justicia vindicatoria.

De acuerdo con esta orientación, se puede dividir el libro en dos partes: la primera, que abarca los once primeros capítulos, en la que Terradas compendia la historia de la justicia vindicatoria y teoriza sobre ella y, por otra parte, los capítulos XII y XIII en los que el autor realiza un estudio particular que, por así decirlo, "integra" todas las fases defendidas en su propuesta; se trata de un estudio sobre los casos del registro judicial de Várad (Hungría) en el primer tercio del siglo XIII.

La obra queda redondeada por la buena elección en el trabajo empírico de Várad. En los últimos capítulos se puede examinar de qué forma procede Terradas, aprovechando el material historiográfico que aportan los estudios previos y en la que, mediante una síntesis entre Lewellyn y Hoebel y la obra de Assier-Andrieu, aboga por una antropología poco dogmática y en franco diálogo con las demás disciplinas. La casuística es la base para establecer una teoría general sobre la justicia vindicatoria.

Terradas no escatima esfuerzos en valorar la labor de sus predecesores, ni tampoco en validar el máximo de fuentes heurísticas, de modo que la comprensión de la relación “jurídica” sea lo más interdisciplinar posible. Uno de los mayores aciertos del autor es la falta de dogmatismo de su propuesta, que toma ejemplo de trabajos tan diferentes como los de Margarita Xanthakou o Antonio Pigliaru ${ }^{17}$.

Lo que interesa finalmente a Terradas es una interpretación de la justicia vindicatoria que evite dos tentaciones que se han acentuado en el siglo XX: la antropología que mira desde la superioridad a las épocas pretéritas y la concepción posmoderna y simbólica que pudiera representar un Clifford Geertz ${ }^{18}$. Consciente de que la "justicia vindicatoria" nos ha llegado principalmente a través de sus corrupciones ${ }^{19}$, Terradas quiere rehabilitar aquellas civilizaciones atendiendo también al estudio de los elementos religiosos o ideológicos, que demasiadas veces han sido tachados como primitivos.

La defensa de la coexistencia de tres fuentes de conocimiento para el estudio concreto de la "justicia vindicatoria" es el núcleo metodológico de la propuesta de

${ }^{17}$ Ibíd., pp. 75 ss.

${ }^{18}$ GeerTZ, C., Local Knowledge, Further Essays in Interpretive Anthropology (New York, Basic Books, 1983). El modelo de Geertz, combinado con el estructuralismo foucaultiano ha inspirado, sin embargo, a algunos importantes historiadores del derecho como HespanHA, A. M., Cultura jurídica europea. Sintesis de un milenio (Madrid, Tecnos, 200)2, pp. 15-72.

${ }^{19}$ Justicia vindicatoria, cit. (n. 1), p. 53. 
Terradas, que trabaja a nivel historiográfico, etnográfico y teórico ${ }^{20}$. Para él, la parte conceptual es el punto de llegada, es decir, su pretensión concluye con el establecimiento de una "teoría general de la justicia vindicatoria".

Para el autor, la sustancia de la justicia vindicatoria se encuentra en la reconciliación. La composición, la ordalía, e incluso el talión, como formas prototípicas de la vindicación, se caracterizan por ser un medio o una herramienta social destinada a cerrar la herida abierta por una situación socialmente anómala. Por eso Terradas recalca que en la justicia vindicatoria no hay víctimas, sino ofendidos. Lo importante es resarcir esa ofensa, una actitud que en muchos casos está emparentada con el perdón, y en otros con la simple voluntad de las partes de buscar un arreglo que permita restablecer una situación lo más parecida posible a la que existía antes de la ofensa.

Como resume Terradas: "se ejerce el derecho vindicatorio cuando la parte que se defendería se integra a un reconocimiento de la naturaleza diversa a la cualidad de la ofensa o daño sufridos. Si el juez ordena un acto vindicativo (que la parte ofendida ejecute un talión) no es porque cede un derecho de esta parte, sino que se le otorga dentro del proceso de restitución de su capacidad para defenderse" ${ }^{21}$. De hecho, la justicia vindicatoria nace de la incapacidad que tiene la parte ofendida para defenderse $^{22}$. Ocurre que, en muchos casos, la justicia vindicatoria se conoce a través de sus corrupciones ${ }^{23}$, en forma de venganza entre clanes por asuntos que no pueden calificarse como de "justicia vindicatoria" 24 .

Para Terradas, es importante comparar la justicia vindicatoria con la que él denomina civil-penal. Las diferencias entre ambas muestran el alcance y la coherencia de este tipo de justicia premoderna. La mayor diferencia entre ambos tipos se encuentra en que el sistema penal "está pensado a partir de la transgresión de la ley, no de la creación de la persona ofendida" 25 .

La importancia del Estado en la tutela de las "ofensas" hizo que él mismo se arrogara la capacidad de ejecutarlas, de modo que las ofensas se vieran progresivamente transformadas en transgresiones a la ley. Terradas prefiere la distinción entre "estado de derecho" y "estados de derecho" para evitar el problema historiográfico que se producía entre las "sociedades con derecho" y "sociedades sin derecho" 26.

El libro se dedica, así pues, a repensar las categorías clásicas de la historia de la antropología. Si en los tres primeros capítulos abunda, como se ha podido ver, la discusión categorial y metodológica, en los siguientes se intenta una explicación histórica

${ }^{20}$ Ibíd., p. 191 y ss.

${ }^{21}$ Ibíd., p. 53.

${ }^{22}$ Ibíd., pp. 106-107.

${ }^{23}$ Ibíd., p. 53-54.

${ }^{24} \mathrm{El}$ esquema estructuralista de Foucault lo conceptúa de una forma muy diferente, "El sistema que reglamenta los conflictos y litigios en las sociedades germánicas de esta época es, por consiguiente, un procedimiento enteramente gobernado por la lucha y la transacción, es una prueba de fuerza que puede terminar en transacción económica. Se trata de un procedimiento que no autoriza a colocar un tercer individuo sobre los dos adversarios a la manera de un elemento neutro que busca la verdad intentando saber cuál de los dos no miente; por lo tanto, nunca interviene en este tipo de sistema un procedimiento de indagación o una investigación de la verdad. Este era el núcleo del Derecho Germánico antes de la invasión del Imperio Romano" Véase: La verdad y las formas jurídicas (Barcelona, Gedisa, 1991), p. 66.

${ }^{25}$ Justicia vindicatoria, cit.(n. 1), p. 167.

${ }^{26}$ Ibíd., p. 169. 
de los tipos de justicia vindicatoria en las diferentes épocas. Antes he apuntado que la obra tiene dos fines, por lo que, a mi juicio, ésta es la explicación más plausible de la organización del libro. En los once primeros capítulos se puede reconocer así una explicación más o menos ordenada de la justicia vindicatoria en sus diferentes tipos, muy pendiente de la discusión de los problemas conceptuales con historiadores, juristas y, sobre todo, con otros antropólogos.

El libro es suficientemente extenso para que esta situación, que parece problemática y propensa a generar confusión, acabe produciendo en el lector una sensación de plenitud y de coherencia cuando lo finaliza. En todo caso, dado el esfuerzo por escribir un libro renovador temática y metodológicamente, se aprecia un sacrificio de la claridad y la separación entre lo teórico, lo historiográfico y lo etnográfico en los once primeros capítulos, que queda compensado por el estudio sobre los registros de Várad que lleva a cabo en los dos últimos capítulos (que abarcan, en total, cuatrocientas páginas).

Así pues, se halla un equilibrio entre la exposición de los materiales etnográficos, históricos y antropológicos, por una parte, y la teoría sobre las diferentes formas de justicia vindicatoria y los problemas metodológicos para explicarla, por otra. Si el primer capítulo es claramente metodológico y conceptual, y examina algunos problemas sobre las obras de Vinogradoff y Durkheim, que he comentado antes, el segundo permite un acercamiento a la obra de Xanthakou y Pigliaru, en la que Terradas encuentra muchos alicientes.

Por otra parte, el tercer capítulo es claramente histórico, y permite reconstruir las imprecaciones, vindictas y ordalías en Grecia ${ }^{27}$. Como contrapartida, el cuarto es un capítulo fundamental, de carácter eminentemente teórico, que discute algunos tópicos de la justicia penal moderna en contraposición con la vindicatoria. Se destacan algunos trabajos sobre el Cáucaso del lingüista Georges Charachidze ${ }^{28}$, y el autor llega a unas conclusiones fundamentales sobre la generalidad de la justicia vindicatoria, que se imponen sobre ciertos particularismos (lugar, época...)

En el quinto, uno de los más importantes, se ve el contraste entre la historiografía y el establecimiento de una "teoría general" de la justicia vindicatoria. El estudio del "núcleo de lo vindicatorio" se encuentra, para Terradas en íntima conexión con el estudio interdisciplinar al que se ha aludido en las páginas anteriores. El ejemplo del derecho de los burgundios le permite avanzar en esa construcción intelectual, que reconstruye algunas importantes categorías historiográficas. De la justicia burgundia no es difícil extrapolar ejemplos que llegan a los Usatges catalanes, corroborando la existencia universal de lo que D. Eduardo de Hinojosa denominó el "elemento germánico"29.

${ }^{27}$ El estudio de Terradas sobre Grecia es un excelente contrapunto a la segunda conferencia de Foucault. Véase: La verdad y las formas jurídicas, cit. (n. 24), 35-59.

${ }^{28}$ Justicia vindicatoria, cit. (n. 1), p. 170 y ss.

${ }^{29}$ Ibíd., pp. 272-296. La idea de que justicia vindicatoria en España tiene origen germánico es un tópico que se repite a lo largo de la gran mayoría de manuales de Historia del Derecho español. La gran mayoría de ellos se basan en esta obra de Hinojosa, que es considerado por muchos el padre de la disciplina en España. Véase: Hinojosa y Naveros, E., El elemento germánico en el Derecho español (Madrid, 1915, reedición en Madrid, Marcial Pons, 1993). Los problemas de la justicia vindicatoria (fundamentalmente la venganza privada y la reconciliación) pueden verse en las pp. 31-69. Una discusión del "elemento germánico" de Hinojosa y un buen ejemplo de teorización sobre los datos empíricos de la "justicia vindicatoria" (duelo, 
No sólo se trata de un particularismo del derecho de los pueblos germánicos, sino un elemento común, que empieza ya en la Biblia ${ }^{30}$ y acaba -o como mínimo, deja de actuar en muchos lugares- en la transición hacia el Renacimiento. De hecho, el capítulo VI trata del talión, de la composición, de la ordalía y del juramento en Mesopotamia y en la Biblia. El capítulo se centra en la reconstrucción composicional del talión, explicando la lógica social y moral que tenía este sistema retributivo tan ridiculizado en los manuales contemporáneos de Derecho Penal.

Un interesante excurso lleva a Terradas a centrarse en la obra jurídica de Maimónides, un filósofo que estudia con perspectiva histórica el derecho judío a la vez que lo compara con el musulmán ${ }^{31}$. Esto permite que Terradas dé una explicación sobre las relaciones del Islam con el mundo vindicatorio. Si la síntesis final sobre el derecho y la justicia concluye con la obra de Maimónides, el estudio de la diya islámica acaba con la obra de Averroes, que Terradas presenta en continua comparación con las sociedades antes expuestas.

El capítulo octavo es una suerte de síntesis teórica sobre la composición, y su diferencia con la idea de responsabilidad civil en tres ámbitos: grado, persona jurídica y responsabilidad estatutaria. Como bien recuerda el autor: "la composición obedece a dos perspectivas para corregir o compensar el daño: hacia el ofendido y hacia el ofensor" ${ }^{\prime 2}$. Para que no se produzcan situaciones de indefensión, en la justicia vindicatoria composicional juega un papel fundamental la equidad, como comentaré más adelante.

Si antes he recalcado que la finalidad de la justicia vindicatoria es cerrar la herida producida por una transgresión social, existen unos "ritos de reconciliación" en diferentes sociedades, que se estudian en el capitulo noveno: andamaneses, Malekula (Vanuatu) y en la Islandia medieval. El capítulo X es un excurso sobre un trabajo de Vladimir Bogoras sobre los chuckhis, en el que Terradas intenta mostrar el carácter moral de las composiciones, por lo que se acaba explicando la reciprocidad como la inclinación natural a seguir las "buenas costumbres" en su particular relación con la administración del Zar.

En el capítulo XI se entra en un tema ligeramente distinto: la justicia vindicatoria cristiana, de la mano de Grégoire de Tours. Con este autor, Terradas se adentra en las ordalías, en las que la composición no se debe a un "arreglo humano" sino a una translación de esa solución a la hermenéutica de la intervención divina en una serie de "pruebas". En el cristianismo, la composición es un problema de la salvación de las almas y de la redención. Si existía indefensión por falta de patrimonio personal, la Iglesia en algunos casos pagaba las cantidades necesarias para que existiera composición. El proceso se tutelaba de forma que las partes llegasen a jurar que no volverían sobre el problema: se tenía que llegar a un acuerdo "definitivo".

Las ordalías, o "juicios de Dios", son una forma de componer no por arreglo humano, sino por la invocación del derecho divino. Quizás la ordalía sea la forma más

reconciliación y ordalía) puede encontrarse en IgLesia Ferreirós, A., El proceso del Conde Bera y el problema de las ordalías, en Anuario de Historia del Derecho Español (1981), pp. 1-222.

${ }^{30}$ En un sentido muy distinto, véase el reciente libro de LEVERING, M., Biblical Natural Law, A Theocentric and Teleological Approach (Oxford, Oxford University Press, 2008), capítulos 2 y 3.

${ }^{31}$ Justicia vindicatoria, cit. (n. 1), 336 ss.

${ }^{32}$ Ibíd., 437. 
compleja de composición, porque se remite a una interpretación de señales divinas ${ }^{33}$. Terradas, oponiéndose a la tradicional consideración de las ordalías como cruenta práctica cristiana ${ }^{34}$, establece un paralelismo con las ordalías de la India y la casuística cristiana. La procedencia pagana está fuera de toda duda. Hincmar, arzobispo de Reims, y Agobardo, obispo de Lyon, discuten su alcance al interpretar que "Deus origo et manifestatio omnis iustitiae (est)" 35 .

Sobre las ordalías, muy bien expuestas por Terradas, podría escribirse mucho. Su examen de la casuística que ofrece los Monumenta Germaniae Historica ${ }^{36}$ le permite llegar a una teoría general sobre las ordalías, que acabaron aboliéndose en el Concilio de Letrán de 1215, cuando entraban en conflicto con el pujante ius commune ${ }^{37}$.

En todo caso, el orden litúrgico de las siete ordalías francas se comenta con extensión y precisión: el juicio por el agua fría, por el agua hirviente, por la olla sobre el fuego, quieta o girante, por el hierro candente, por el pan y el queso, por el pan pendiente y por el libro de los salmos ${ }^{38}$. La ordalía implica, según el autor, "que el reo sólo puede confiar en Dios, y el pueblo cristiano en sus señales" 39 .

La liturgia ordálica de Várad es fiel a las ordalías francas, y Terradas concluye su obra con un comentario selecto a los principales problemas que manifiesta. Es aquí donde el profesor catalán reivindica su método y la coherencia en la interpretación que reúne datos jurídicos, históricos y sociales, rematados por un conocimiento de las fuentes directas que Terradas tuvo en Hungría. El resultado es la sistematización de esos juicios de Dios como obra cumbre de la literatura vindicatoria.

Sólo tras la lectura de esos casos, en los que Terradas opera siguiendo el método de Lewellyn, al que añade toda una serie de materiales históricos medievales y un cabal conocimiento de la justicia civil y canónica, a la vez que de la teología, se puede aprehender en su justo valor el alcance de este libro. Si las ordalías de Várad representan el canto del cisne de la justicia vindicatoria, Terradas las reivindica como un poliedro en donde aparecen la mayoría de problemas y sus soluciones, antes de que el Estado Nación se impusiera ${ }^{40}$.

${ }^{33}$ Aquilino Iglesia, sobre los datos empíricos del derecho español, concluye que "La ordalía es el último recurso al que se puede acudir, cuando no existen pruebas o cuando se duda de la veracidad del juramento del testigo. Un empleo, por tanto, muy restringido, que se verá todavía más limitado por las prohibiciones eclesiásticas”, cit. (n. 29), p. 221.

${ }^{34}$ Bartlett explica el origen pagano de esta práctica, que generó muchísimos debates en el seno de la Iglesia. En todo caso, la antropología jurídica de la Antigüedad y de la Edad Media tendría a la ordalía como práctica de muchas culturas. Véase: BARTLETT, R., Trial by Fire and Water. The Medieval Justice Ordeal (Oxford, Clarendon Press, 1986), esencialmente, pp. 154-156.

${ }^{35}$ Justicia vindicatoria, cit. (n. 1), p. 568 ss.

${ }^{36}$ Zeumer, K., Formulae Merowingici et Karolini Aevi. Accedunt Ordines Iudiciorum Dei (Hannover, Hahnsche Buchhandlung, 1886). Véase: Justicia vindicatoria, cit. (n. 1), p. 597.

${ }^{37}$ Justicia vindicatoria, cit. (n. 1), p. 600.

${ }^{38}$ Ibíd., p. 606.

${ }^{39}$ Ibíd., p. 643.

${ }^{40}$ Véanse algunas dificultades desde la transición de la "justicia vindicatoria" hasta la "justicia moderna” en Vallerani, M., La giustizia pubblica medievale, pp. 28 ss . Vallerani hace mención de algunos elementos vindicatorios en el derecho procesal tardomedieval italiano, tales como el juramento o la labor de pacificación de los juristas, que poco a poco van desdibujando la ofensa personal para convertirla en delito público. 
Si hasta aquí he comentado, al hilo de la exposición temática de los capítulos, los problemas historiográficos, metodológicos y conceptuales de la obra, quisiera terminar con una serie de consideraciones de carácter ideológico, que pueden revestir cierto interés para los estudiosos del derecho.

\section{LA IDEOLOGÍA DE LA VINDICACIÓN}

Más allá del esfuerzo de recopilación y de teorización, se debe alabar en la obra de Terradas su afán en la comprensión del mundo vindicatorio y de sus constantes antropológicas. La precaución metodológica se opone tanto a ciertas derivas de la antropología francesa, como a la antropología colonial o la posmoderna. Terradas, sin rechazar completamente las ideas del estructuralismo o del funcionalismo, se sitúa en una posición integradora que, si resulta algo incómoda en el campo de la antropología, lo es más en el de la historia o la filosofía del derecho.

Desde un prisma ideológico, se podría distinguir entre una justicia vindicatoria divina y humana, algo que Terradas no hace de forma específica, pues tiende a buscar la base social y antropológica más que a indagar la etiología de esas fuentes ${ }^{41}$. En todo caso, creo que la distinción podría ser válida, pues separaría los casos en los que la solución del conflicto se encuentra en el entendimiento entre las partes de los que media la justicia divina. No es lo mismo que la solución la otorgue un juez, autorizando una venganza o facilitando una composición económica o matrimonial, que la hermenéutica de la voluntad divina.

Tampoco es lo mismo cuando el juez es la sociedad en conjunto, como puedan ser los chuckchis en el caso de su particular relación con la Administración. ¿Ante quién acudían los chuckchis para ejecutar su venganza particular? Resulta más bien un malentendido cultural aunque, en todo caso, entra en la categoría de justicia vindicatoria porque cumple con el requisito del condicionamiento moral o social para corresponder con acciones frente al "ofensor".

Sin embargo, la diferencia entre la ará o la ordalía de una simple composición de carácter económico radica en que el ofendido impetra de la divinidad, no tanto la ayuda para ejecutar, sino su protección para cumplir con su deber ${ }^{42}$. La ordalía es un modo muy particular y complejo de justicia vindicatoria útil cuando no hay pruebas, pues en él la divinidad tiene que manifestarse fehacientemente en el seno de la liturgia, en forma de prueba. Esta prueba, naturalmente, sería inaceptable para la actual jurisprudencia bienpensante, caracterizada por su alarde de racionalidad y de progresiva evolución ${ }^{43}$.

La mentalidad antievolucionista de Terradas le impide dialogar con muchas de las corrientes imperantes en la historiografía del pensamiento jurídico desde Hegel.

\footnotetext{
${ }^{41}$ Un desarrollo de esta cuestión puede verse en PRODI, P., Justicia de los hombres, justicia de Dios, en Una historia de la justicia. De la pluralidad de fueros al dualismo moderno entre conciencia y derecho (Madrid, Katz, 2008), pp. 21-54.

${ }^{42}$ Justicia vindicatoria, cit. (n. 1), p. 118.

${ }^{43}$ Legros, H., Quand les jugements de Dieu deviennent des artifices littéraires, ou la profanité impunie d'une rhétorique, en La justice au Moyen Âge, sanction ou impunité? (Aix-enProvence, Presses de l'Université de Provence, 1986), pp. 197-213. Según Legros la función de las ordalías no sólo es jurídica sino también moral, y tiene un valor universal porque toda la sociedad cree en ellas.
} 
El problema categorial que afecta a la explicación de la evolución del derecho es el sacrificio que se hace de los componentes de cualquier otra relación social que no esté ligada a lo que modernamente se entiende por "derecho" o "justicia" ${ }^{4}$. Con su reivindicación, Terradas no se sitúa a la vera de la arqueología foucaultiana, que busca el derecho en las construcciones sociales a partir de la no-racionalidad, sino que reivindica un concepto más amplio de "derecho", en el que puedan caber modelos en el que la tutela jurisdiccional no es estrictamente estatal, ni civil ni penalmente.

Si Foucault se oponía a la tradición racionalista posthegeliana, y proponía una búsqueda en la alteridad, Terradas considera que hay un derecho y una justicia que tradicionalmente no se ha considerado como tal, y que tiene una gran centralidad, hasta el punto que deviene la pauta de cualquier antropología jurídica. Su defensa de la justicia vindicatoria como derecho necesita de un esquema realista que sea capaz de enjuiciar si tales o cuáles actos tienen "sabor a derecho" pese a que actualmente no sean considerados como actos jurídicos. Lewellyn es el autor que, según Terradas, rompe las categorías del derecho de la Modernidad, al buscar unos esquemas más amplios para encasillar "lo jurídico" del resto de las sociedades.

El esquema que defiende Terradas sería, si se me permite la expresión, un "iusnaturalismo sociológico" o "iusnaturalismo antropológico". Realmente, lejos de considerar un fundamento teológico del derecho, el autor parte de algo tan empírico y material como los "casos-problema", y busca una conceptualización del derecho común en todas las sociedades. La conclusión es que en todas las sociedades hay un anhelo de justicia, más allá de lo que puedan marcar las leyes de turno, si es que las hay.

La recopilación y comparación de las soluciones dadas por diferentes pueblos a los mismos problemas muestra que el ser humano -imaginamos que por una necesidad antropológica- busca justicia, de modo que todas las normas sociales deben ser corregidas sobre la base de la equidad.

Esta es la conexión fundamental de Terradas con la obra de Vinogradoff, que defiende un iusnaturalismo basado en la epieiqueia aristotélica ${ }^{45}$, es decir, que el sentido común -llámese, si se quiere sentido social- es lo que ajusta cada norma o costumbre a una dimensión de justicia o de reparación necesaria. Cuando Supiot carga contra el positivismo jurídico, denunciando la miseria moral a la que conduce la falta de realismo antropológico, está pensando en que la idea de coerción estatal es una gran ficción jurídica ${ }^{46}$.

Desde el positivismo jurídico, las tesis de Terradas son absolutamente inaceptables, pues representan un golpe demasiado duro a un edificio resguardado de todo contacto con lo no estrictamente jurídico. Para un positivista como Kelsen o Austin, sólo el jurista puede definir lo jurídico, y no necesita de ningún antropólogo para aleccionarle.

La "antropología jurídica” de Terradas se instala en la línea crítica que actualmente defiende Supiot, y que halla sus raíces en Vinogradoff. Que en las sociedades antiguas se encuentren toda una serie de conductas aprobadas y reprobadas indica la íntima conexión del derecho con la moral, extremo negado por el positivismo jurídico desde

\footnotetext{
${ }^{44}$ Massini Correas, C. I., La teoría del Derecho Natural en el tiempo posmoderno, en Doxa, Cuadernos de Filosofía del Derecho, 21 (1998) 2, pp. 289-304.

${ }^{45}$ Véase Vinogradoff,,P., cit. (n. 13), cap. VIII; Justicia vindicatoria, cit. (n. 1), p. 433.

${ }^{46}$ Supiot, A., Homo juridicus. Essai sur la fonction anthropologique du Droit (Paris, Editions du Seuil, 2005), especialmente, pp. 108-125.
} 
Austin hasta Hart. Terradas añade que "...se suele decir: "lo que es justo en una cultura es injusto en otra y lo que unos ven como bueno otros lo ven como malo". No es así: en todas las culturas se reconoce el homicidio o el incesto y sus autores deben responder por ello de uno u otro modo" ${ }^{47}$. Unas líneas antes, el autor reconoce que "toda cultura jurídica posee el acto de jurar junto con la repulsión del perjurio" 48 .

Estas frases son un espaldarazo para los defensores del derecho natural, y de la existencia de absolutos morales ${ }^{49}$. Hay bienes moralmente compartidos en todas las sociedades, en las que varía precisamente la forma en la que se protege jurídicamente cada uno de ellos. Lo que no cambia es la sed de justicia, y el cara a cara que el ofendido mantiene frente al ofensor en presencia de la sociedad. No se trata de un derecho natural revelado por Dios, sino una actitud típicamente humana que, en muchas ocasiones coincide -no casualmente- con los textos revelados o con los oráculos divinos.

La oposición antropológica a los derechos humanos y a una justicia universal se encuentra en la falsedad de sus premisas ${ }^{50}$, muy cuestionables - como recuerda Vinogradoff $^{51}$ - desde la propia práctica del derecho y del sentir jurídico de los pueblos. Y todos ellos se hermanan en el hecho de implorar justicia frente a una autoridad respetada por las partes, sea ésta un monarca, un juez, la sociedad o Dios ${ }^{52}$. La queja de los ofendidos abre el "proceso vindicatorio", y le da pie a una actuación para resarcirse de esa ofensa.

Así, Terradas recuerda que "nosotros interpretamos que muchos procesos tratados por historiadores, juristas o antropólogos como extrajudiciales en la Antigüedad, la época medieval o las sociedades tradicionales, son realmente judiciales, con juicio, con un procedimiento de búsqueda y aplicación de justicia" ${ }^{33}$. El autor rehabilita asimismo la importancia de la parte ofendida para actuar en el juicio. No se trata de la "autotutela", valorada en los manuales de derecho procesal como propia de las

${ }^{47}$ Justicia vindicatoria, cit. (n. 1), p. 27.

${ }^{48}$ Ibíd.,

${ }^{49}$ Por ejemplo, Finnis, J. M., Moral Absolutes. Tradition, Revision, and Truth (Washington D.C., The Catholic University of America Press, 1991).

${ }^{50}$ MacIntyre, A. C., Tras la virtud (Barcelona, Crítica, 1987), p. 95 [sobre los derechos humanos] "no existen tales derechos y creer en ellos es como creer en brujas y unicornios".

${ }^{51}$ Véase, Vinogradoff, P., cit. (n. 13), cap. IX.

${ }^{52}$ Terradas se opone una vez más a la visión foucaultiana, "Para que hubiese un proceso penal era necesario que hubiese habido daño, que al menos alguien afirmase haber sufrido daño o se presentase como víctima y que esta presunta víctima designase su adversario. La víctima podía ser la persona directamente ofendida o alguien que, perteneciendo a su familia, asumiese la causa del pariente. La acción penal se caracterizaba siempre por ser una especie de duelo u oposición entre individuos, familias, o grupos. No había intervención alguna de ningún representante de la autoridad, se trataba de una reclamación de un individuo a otro que se desarrollaba con la sola intervención de estos dos personajes, el que se defiende y el que acusa. Conocemos sólo dos casos bastante curiosos en que había una especie de acción pública, la traición y la homosexualidad. En estos casos intervenía la comunidad, que se consideraba lesionada, y colectivamente exigía reparación a un individuo. Por lo tanto la primera condición que observamos para que hubiera acción penal en el antiguo Derecho Germánico era la existencia de dos personajes y nunca tres". Véase M. Foucault, La verdad $y$ las formas jurídicas, cit. p. 65.

${ }^{53}$ Justicia vindicatoria, cit., p. 58. 
sociedades primitivas ${ }^{54}$, sino de la legitimación que da el juez a la parte ofendida para emprender su acción jurídica ${ }^{55}$.

No hay que confundir tampoco esa posibilidad de defender sus intereses como un arreglo extrajudicial o arbitraje. El juez aquí no es un mediador ni un árbitro al que las partes voluntariamente se someten -para eludir, como se hace actualmente, la justicia estatal y crear una lex mercatoria paralela- sino precisamente la encarnación del tercero imparcial que vigila que en la sociedad pueda cerrarse la brecha que se ha abierto por culpa de una transgresión.

$Y$ es que en la cultura vindicatoria existen una serie de valores compartidos que, en el ámbito de la justicia civil-penal moderna se han ido perdiendo. Esta aserción, que es un corolario de las tesis del libro, sería inaceptable para muchos civilistas y penalistas de la actualidad. Si se estudia el derecho penal contemporáneo, que se opone casi unánimemente al retribucionismo ${ }^{56}$, se puede observar que los ofensores y los ofendidos no están obligados a llegar a un acuerdo. Es el Estado hobbesiano quien juzga a los ofensores y, en su caso, les impone una condena. No es necesario que exista el perdón y la reconciliación, ni que se cierren las heridas.

No quiero ni pensar en los casos en los que, por falta de condena o por una condena insuficiente, la parte ofendida ha visto burlada su pretensión de justicia. Ante los Tribunales, que son -hoy por hoy- la única vía legal para impartir la justicia penal, han sido muchas las víctimas que han ido en vano a pedir y hasta suplicar justicia para un familiar, un amigo o un vecino. La legitimación que antes daba la sociedad, la da actualmente un Leviatán -arbitrario en más de una ocasión-, que deja procesalmente inermes a muchos ofendidos y, lo que es peor, moralmente insatisfechos.

Conviene, por tanto, no desdeñar ni despreciar todo lo que pueda aportar el modelo de la justicia vindicatoria. No hay duda de que muchas de sus caracterizaciones son inaceptables para la sociedad actual, pero no hay que olvidar que la antropología comparada de estas sociedades ayuda a comprender el verdadero anhelo de justicia que alberga el ser humano, y que muchas veces trasciende, para decirlo con Marx, la mera superestructura en la que vive.

\section{CONCLUSIONES}

En todo caso, una clasificación antropológica de los principales tipos y subtipos de elementos de la justicia vindicatoria es una labor que hubiese tenido mayor alcance si la disciplina de la "antropología jurídica" estuviese ya metodológica y conceptualmente asentada. Visto el excelente resultado del libro, que ha sembrado una semilla definitiva para la germinación de futuros trabajos de "antropología jurídica", sería muy deseable que el profesor Terradas escribiese un manual de la disciplina en el que, después de esta obra sobre la justicia vindicatoria, presentara unas conclusiones definitivas y unas directrices claras de la antropología jurídica para los estudiosos de la antropología, de la historia y del derecho.

Justicia vindicatoria representa el enorme esfuerzo de establecer un método, un objeto y unas directrices para el estudio de la antropología jurídica en general, y de la

\footnotetext{
${ }^{54}$ Por ejemplo, Oliva Santos, A. - Díez-Picazo Giménez, I. - Vegas Torres, J., Derecho procesal. Introducción (Madrid, Centro de Estudios Ramón Areces, 2004), p. 23.

${ }^{55}$ Justicia vindicatoria, cit. (n. 1), p. 59.

${ }^{56}$ Ferrajoli, L., Derecho y razón. La teoría del garantismo penal (Madrid, Trotta, 2005).
} 
justicia vindicatoria, en particular. No hay duda de que representa un gran beneficio para los estudiosos del derecho y del pensamiento jurídico, pues conocen una forma de colaborar estrechamente con los historiadores y los antropólogos, a la vez que éstos pueden tratar con datos jurídicos con mayor precisión, configurando un proceder más abierto a la realidad interdisciplinar de las ciencias sociales.

Concluyendo: son muchas las cuestiones que podrían comentarse sobre este volumen de Ignasi Terradas. Me he ceñido a algunos aspectos muy generales, y siempre con la vista puesta en el posible diálogo transversal que el autor propone y que me parece digno de la mayor alabanza. Para un jurista, se trata de una lectura profiláctica y liberadora de unos prejuicios que están, en muchas ocasiones, demasiado arraigados. Se trata, aún así, de una labor imprescindible si el derecho quiere dialogar con las ciencias sociales.

El autor ha querido adentrarse en el mundo del derecho con respeto y con un buen conocimiento de la materia, y ha mostrado un camino practicable y sensato a los antropólogos, que huye de los dogmatismos y busca estrechar relaciones con los demás saberes. Esperemos que, por su parte, los juristas no declinen la amable invitación a colaborar, ni la oportunidad de repensar su propia historia.

En fin, libros como el de Ignasi Terradas ennoblecen el quehacer de los investigadores que se encuentran en la frontera de varias disciplinas, a la vez que muestran -con gran brillantez- los puntos de convergencia entre todas ellas. 